\title{
Saludo del Presidente de la SHAORL
}

Mis cordiales saludos, en Pucón/Chile, a los organizadores del Joint Meeting entre ORL Chile y SHAORL a realizarse por primera vez en territorio latinoamericano del 3.-6.12.2008. Este congreso es un estreno, aun cuando ya desde el 2001, mediante el "Proyecto Latinoamérica" la SHAORL ha hecho enormes esfuerzos y también progresos para despertar el interés de los colegas latinoamericanos e integrarlos. La atractividad de la SHAORL consiste también en que tanto los colegas de habla alemana como también los colegas de habla española puedan disertar y discutir en su propio idioma en todos los congresos. Debido a que en la constelación EuropaLatinoamérica se presentan pocas posibilidades en forma de congresos y simposios, la SHAORL ofrece con sus congresos alternantes de cada 2 años entre Alemania y España, un interesante foro científico y clínico para médicos ORL socios de ambos idiomas. Los últimos congresos, y en especial el de septiembre 2007 en Freiburg mostraron una atmósfera de entusiasmo. Nunca ha sido el número de participantes latinoamericanos a un congreso SHAORL tan alto como el del año pasado, y también el número total de congresistas superó el, hasta entonces, margen ideal notablemente. Esto es un alto testimonio para nuestra Sociedad y es también un estímulo para continuar con éxito el trabajo empezado.

Entre los congresistas latinoamericanos participantes en Freiburg, presentaron los médicos ORL chilenos la fracción más numerosa. Esto también muestra el desarrollo positivo en los últimos años; así es que, no es sorprendente que el primer Congreso de la SHAORL junto con una sociedad ORL latinoamericana tenga lugar en Pucón/Chile.

Orientados por los numerosos invitados y la gran cantidad de disertaciones y pósters nacionales e internacionales registrados, los organizadores chilenos han confeccionado un programa de alta calidad científica y gran expectativa. No hay duda que el programa colateral también será organizado perfectamente por el Comité Organizador chileno con el arte típico profesional del mismo, para alegría de los congresales.

En este lugar me permito, como presidente de la SHAORL, agradecer y felicitar a colegas chilenos, en especial al Comité Organizador local por su actividad incansable, la cual, no dudo, ha de llevar este primer Joint-Meeting a un éxito grandioso. Como perspectiva, quisiera anunciar el $8^{\circ}$ congreso de SHAORL que se celebrará del 10.-12.9.2009 en San Sebastián/España bajo la dirección del Prof. Algaba.

Deseo a todos los participantes de cerca y lejos una estadía agradable en Pucón, con un congreso vivaz, con muchas oportunidades para discutir e intercambiar ideas. Este Congreso en realidad debe ser considerado como orientación para el futuro. Nosotros nos alegramos sobre cada participante que asista a esta "Premiere".

Atentamente

Prof. Dr. Dr. h.c. R. Laszig

Präsident SDGHNO 